\title{
Genes qnr en Enterobacteriaceae aisladas en un hospital de Venezuela
}

\author{
José García, Dianny Martínez, Luisa Caña, Diorelis González, Lucy Rodríguez, \\ Hectorina Rodulfo, Marcos De Donato y Militza Guzmán
}

\section{$q n r$ genes in Enterobacteriaceae isolated from at a hospital in Venezuela}

Background: Enterobacteria resistant to quinolones is increasing worldwide, including Venezuela. The mechanism for this resistance could be due to genes included in the chromosome or in transmissible plasmids. Aim: To evaluate the resistance to quinolones, coded by $q n r$ genes present in enterobacteria species, isolated in the University Hospital of Cumana, Venezuela. Methods: Antimicrobial susceptibility tests to quinolones, beta-lactams and aminoglycosides were carried out to all the isolates. The presence of $q n r$ genes were determined by PCR. The isolates carrying the $q n r$ genes were used for bacterial conjugation tests to determine the presence of transferable plasmids. Antimicrobial susceptibility tests and PCR were carried out in the transconjugants to verify the transfer of the genes. Results: High levels of antimicrobial resistance to quinolones and beta-lactams were found among the isolates. We found that $33.6 \%$ of the isolates carry the $q n r \mathrm{~B}$ gene and $0.9 \%$ qnrA gene. Of the 23 transconjugants, 20 showed to have qnrB gene, but none qnrA. Discussion: We concluded that the high frequency of $q n r$ genes found in the enterobacteria isolates and their presence on transferable plasmids, complicate the use of quinolones for the treatment of bacterial infections, thus, a treatment plan should be designed with the rational use and the rotation of different types of antimicrobials, in order to avoid the selection of increasingly resistant strains.

Key words: Enterobacteria, quinolones, qnr.

Palabras clave: Enterobacterias, quinolonas, qnr.

\section{Introducción}

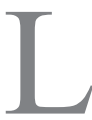
as quinolonas son un grupo de antimicrobianos sintéticos que ejercen su actividad bactericida uniéndose a las topoisomerasas bacterianas e inhibiendo su función ${ }^{1}$. Las primeras quinolonas (ácido nalidíxico, cinoxacina y ácido oxolínico), fueron introducidas en la década de los 60' para tratar infecciones urinarias causadas por bacilos gramnegativos. La adición de un sustituyente fluoruro al anillo principal de las quinolonas, dio origen a las fluoroquinolonas, las que presentan un amplio espectro de actividad antibacteriana y ha permitido agruparlas en generaciones, tomando en cuenta su época de aparición y su espectro antibacteriano ${ }^{2,3}$.

Desde la introducción de las fluoroquinolonas, la resistencia de las enterobacterias a estos agentes se ha hecho frecuente en todo el mundo ${ }^{3}$. Dicha resistencia, normalmente es producto de alteraciones cromosómicas, aunque también se ha asociado a la captación de genes mediante transferencia de plásmidos ${ }^{4,5}$. La resistencia codificada en el cromosoma ocurre por mutaciones en ciertas regiones de las topoisomerasas (ADN girasa y topoisomerasa IV), denominadas regiones determinantes de la resistencia a quinolonas o QRDRs (del inglés “quinolone resistance determining regions") ${ }^{4}$.
La resistencia a quinolonas mediada por plásmidos (RQMP), ha sido reportada en diversas partes del mundo $^{6,7,8}$. El primer reporte se confirmó en 1998 en una cepa clínica de Klebsiella pneumoniae, aislada de un cultivo de orina en Birmingham, Alabama (E.U.A.). El gen responsable de la resistencia adquirida se denominó qnr, el que codifica para una proteína denominada Qnr que actúa uniéndose y protegiendo a la girasa y a la topoisomerasa IV de la acción de las quinolonas ${ }^{3,5}$.

Se han descrito, al menos, seis variantes del gen $q n r(q n r \mathrm{~A}, q n r \mathrm{~B}, q n r \mathrm{~S}, q n r \mathrm{C}, q n r D \mathrm{y} q n r \mathrm{VC})$ cuyas secuencias nucleotídicas difieren en $40 \%{ }^{5,9}$. La RQMP también puede ser codificada por otros genes entre los que destacan, el gen $a c c\left(6^{\prime}\right)-I b-c r$, que codifica una variante aminoglucósido acetiltransferasa, capaz de inactivar ciprofloxacina a través de la acetilación de su sustituyente piperazinil; y los genes $o q x \mathrm{AB}$ y qep $\mathrm{A}$, que codifican bombas que expulsan quinolonas ${ }^{10}$.

La resistencia a quinolonas relacionada a mutaciones cromosómicas va a conferir a las bacterias que las presenten resistencia de alto nivel a estos antimicrobianos, mientras que el grupo de genes pertenecientes a la RQMP, van a codificar determinantes de resistencia que inducen aumentos de la concentración inhibitoria mínima (CIM), que no alcanzan los puntos de corte considerados como
Hospital Universitario

"Antonio Patricio de Alcalá" Cumaná, Venezuela.

Laboratorio de Bacteriología, (JG $D M, L C, D G, L R$ )

Universidad de Oriente, Núcleo de Sucre, Cumaná, Venezuela.

Departamento de Bioanálisis (MG).

Postgrado en Biología Aplicada, (JG, DM)

Instituto de Biomedicina y Ciencias Aplicadas Dra. "SusanTai" Cumaná, Venezuela.

Laboratorio de Genética Molecular (HR, MDD).

Escuela de Ingeniería y Ciencias, Queretaro, México. Tecnológico de Monterrey (HR, MDD)

Los investigadores declaramos que no existe conflicto de intereses.

Esta investigación fue parcialmente financiada por el proyecto Misión Ciencia (G2007001442)

Recibido: 13 de mayo de 2017 Aceptado: 30 de enero de 2018

Correspondencia a:

José García A.

jfgarciaavila@hotmail.com 
resistentes, facilitando la selección de mutantes con mayores niveles de resistencia a nivel cromosomal ${ }^{4,10}$.

Los genes $q n r$ han sido reportados en enterobacterias como K. pneumoniae, Citrobacter freundii, Enterobacter spp., Escherichia coli, Providencia stuartii y Salmonella spp., aisladas de muestras clínicas ${ }^{11,12}$.

En los últimos años, en Venezuela, se ha observado un incremento en los porcentajes de resistencia a quinolonas, específicamente a ciprofloxacina. En el Estado Mérida, fue reportado $4,7 \%$ de genes $q n r \mathrm{~B}$, en un estudio realizado en 127 cepas de Salmonella enterica ${ }^{13}$.

Debido al elevado porcentaje de cepas resistentes reportado en los últimos años, y que dicha resistencia puede estar codificada por plásmidos transferibles, las que pueden ser portadoras de otros determinantes de resistencia, se propuso el siguiente trabajo de investigación: Evaluar fenotípicamente la resistencia a quinolonas y la presencia de los genes $q n r \mathrm{~A}, q n r \mathrm{~B}$ y $q n r \mathrm{~S}$, así como su capacidad de transferencia, en cepas de enterobacterias aisladas de pacientes asistidos en los servicios médicos del Servicio Autónomo Hospital Universitario "Antonio Patricio de Alcalá" (SAHUAPA), de la ciudad de Cumaná, Estado Sucre, Venezuela.

\section{Material y Método}

\section{Cepas bacterianas e identificación bioquímica}

Se evaluaron 104 cepas no duplicadas de enterobacterias recolectadas durante el período de enero a junio de 2014 de pacientes estudiados en el Laboratorio de Bacteriología del SAHUAPA. La caracterización bioquímica de las cepas se realizó mediante los protocolos de identificación convencionales para bacterias gramnegativas fermentadoras y no fermentadoras de lactosa ${ }^{14,15}$.

\section{Evaluación de susceptibilidad antimicrobiana}

Se determinó la susceptibilidad a los antimicrobianos de acuerdo al método de difusión con discos, siguiendo los lineamientos establecidos por el Instituto de Estándares de Laboratorios Clínicos (CLSI) ${ }^{16}$. Se ensayaron los siguientes antimicrobianos: ciprofloxacina $(5 \mu \mathrm{g})$, ácido nalidíxico $(30 \mu \mathrm{g})$, levofloxacina $(5 \mu \mathrm{g})$ y norfloxacina $(10 \mu \mathrm{g})$. Con la finalidad de evaluar resistencia asociada, se emplearon discos de cefotaxima $(30 \mu \mathrm{g})$, ceftazidima $(30 \mu \mathrm{g})$, cefepima $(30 \mu \mathrm{g})$, aztreonam $(30 \mu \mathrm{g})$, imipenem $(10 \mu \mathrm{g})$, meropenem $(10 \mu \mathrm{g})$, gentamicina $(10 \mu \mathrm{g}) \mathrm{y}$ amikacina $(10 \mu \mathrm{g})$, todos de la marca Oxoid.

\section{Detección de los genes qnrA, qnrB y qnrS mediante reacción de polimerasa en cadena (RPC)}

La extracción de ADN genómico se llevó a cabo mediante el kit de purificación Wizard Genomic DNA (Promega), siguiendo las especificaciones del fabricante.
Para llevar a cabo la reacción de polimerasa en cadena (RPC), se empleó 12,5 $\mu 1$ de la Master Mix PCR (Promega), 2,5 $\mu \mathrm{l}$ de los oligonucleótidos respectivos $q n r \mathrm{~A}^{17}(\mathrm{~F}$ 5'-TCAGCAAGAGGATTTCTCA-3' y R 5'- GGCAGCACTATTACTCCCA -3'), qnrB B ${ }^{18}$ (F 5'- GATCGTGAAAGCCAGAAAGG-3' y R 5'-ACGATGCCTGGTAGTTGTCC-3'), $q n r \mathrm{~S}^{19}$ (F 5'- ACGACATTCGTCAACTGCAA -3' y R 5'-TAAATTGGCACCCTGTAGGC-3'), $1 \mu \mathrm{l}$ de ADN genómico bacteriano y $6,5 \mu \mathrm{l}$ de agua destilada estéril libre de nucleasas, para un volumen total de reacción de $25 \mu 1$. La desnaturalización inicial se llevó a cabo a $94^{\circ} \mathrm{C}$ durante $4 \mathrm{~min}$, con 30 ciclos repetidos de desnaturalización a $94^{\circ} \mathrm{C}$ por $45 \mathrm{seg}$, hibridación a $53{ }^{\circ} \mathrm{C}$ por $45 \mathrm{seg}$ y extensión a $72{ }^{\circ} \mathrm{C}$ durante $60 \mathrm{seg}$, con un ciclo de extensión final a $72{ }^{\circ} \mathrm{C}$ por $5 \mathrm{~min}$, utilizando un termociclador Master Cycler $^{17,18}$. Los productos de amplificación se sometieron a electroforesis en gel de agarosa al $1 \%$, luego se tiñeron con bromuro de etidio $(0,5 \mu \mathrm{g} / \mathrm{ml})$ en tampón TBE $1 \mathrm{X}$ durante $30 \mathrm{~min}$ a $10 \mathrm{~V} /$ $\mathrm{cm}$. Para estimar el tamaño de los fragmentos de ADN resultantes, se utilizó un marcador de tamaño molecular $1 \mathrm{~Kb}$ Plus (Invitrogen). Finalmente fueron observados por transiluminación con luz ultravioleta y fotografiados.

\section{Conjugación bacteriana}

El proceso se realizó empleando la técnica sobre filtro $^{19}$. Como receptora se empleó la cepa $E$. coli J62-2 (F-, his, , pro-, trp', lac', rif $\left.^{+}\right)$. Se seleccionaron transconjugantes en placas de agar tripticasa de soya (TSA) que contenían rifampicina $(100 \mu \mathrm{g} / \mathrm{ml}$; Pfizer $)$ y ciprofloxacina $(0,06 \mu \mathrm{g} / \mathrm{ml} \text {; Pfizer })^{18,20}$. La resistencia transferida a la cepa receptora se verificó por el método de difusión con discos, según los lineamientos establecidos por el $\mathrm{CLSI}^{16}$, ensayando la misma galería de antimicrobianos empleados con las cepas clínicas.

\section{Verificación de los determinantes transferidos}

A las cepas clínicas que amplificaron para el gen qnr, y sus respectivas trans-conjugantes se les realizó extracción de ADN plasmídico, empleando el kit de purificación FavorPrep (Favorgen), según las especificaciones del fabricante. Con el propósito de constatar la ubicación plasmídica de dichos genes, se realizó una nueva RPC, atendiendo a las mismas condiciones descritas con anterioridad.

\section{Control de calidad}

Se emplearon las siguientes cepas: E. coli $\mathrm{ATCC}^{\circledR}$ 25922, como control de discos de antimicrobianos. Como control positivo de RPC, se empleó un lisado de la cepa $K$. pneumoniae UAB1, la que presenta el gen qnrA, la cepa $K$. pneumoniae 168 como control positivo para el gen $q n r \mathrm{~B}$ y la cepa $K$. pneumoniae 66 como control positivo para $q n r \mathrm{~S}$. Las cepas fueron donadas por el Laboratorio 


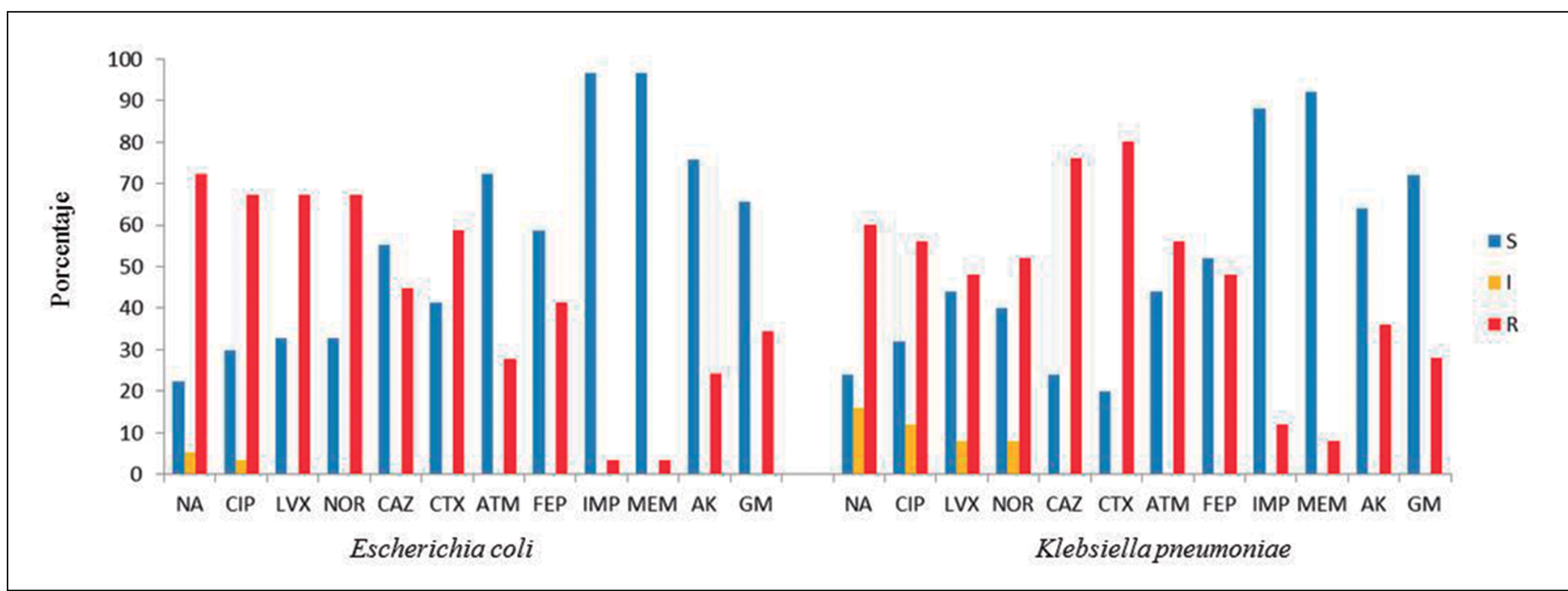

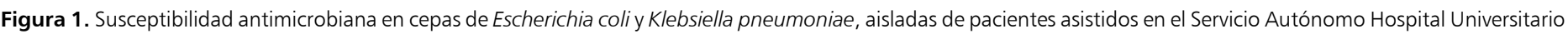

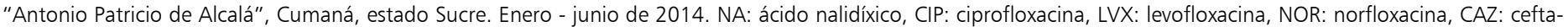

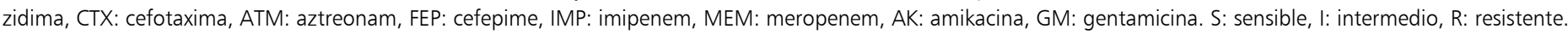

de Biología de Plásmidos de la Universidad Central de Venezuela (UCV).

\section{Análisis de datos}

El análisis de los resultados se realizó mediante estadística descriptiva, empleando porcentajes de frecuencias, para ello, se elaboraron tablas y figuras de los datos obtenidos mediante el programa estadístico SPSS versión $11.5^{21}$.

\section{Resultados}

De las 104 enterobacterias recolectadas en el presente estudio, se identificaron 11 especies, siendo $E$. coli la más frecuente $(55,8 \%)$, seguida por $K$. pneumoniae $(24,0 \%)$; se presentaron en menor frecuencia Klebsiella oxytoca, Enterobacter aerogenes, C. freundii, Proteus vulgaris y Pantoea agglomerans (datos no mostrados).

Las pruebas de susceptibilidad antimicrobiana ante las quinolonas, de las cepas de E. coli y $K$. pneumoniae (las aisladas en mayor número), revelaron elevados porcentajes de resistencia a todas las quinolonas ensayadas. Escherichia coli presentó 72,4 y $67,2 \%$ de resistencia a ácido nalidíxico y ciprofloxacina, respectivamente, mientras que $60,0 \%$ de las cepas de $K$. pneumoniae, mostraron resistencia al ácido nalidíxico y $56,0 \%$ a ciprofloxacina.

Se observaron elevados porcentajes de resistencia a los $\beta$-lactámicos ensayados, mientras que aminoglucósidos y carbapenémicos se mostraron como una buena opción terapéutica ante las cepas estudiadas (Figura 1).
Los resultados de la RPC revelaron la presencia de genes $q n r \mathrm{~A}$ y $q n r \mathrm{~B} ; 33,6 \%(35 / 104)$ presentaron el gen $q n r \mathrm{~B}(460 \mathrm{pb})$ y $0,9 \%(1 / 104)$ el gen $q n r \mathrm{~A}(625 \mathrm{pb})$. No se demostró co-existencia de los genes estudiados (Figura 2). $\mathrm{El}$ gen qnr $\mathrm{B}$, se presentó con mayor frecuencia en $E$. coli $(45,7 \%)$ y $K$. pneumoniae $(37,1 \%)$. Mientras que, qnrA sólo se detectó en una cepa de P. vulgaris (Tabla 1). Del total de cepas con el gen $q n r \mathrm{~B}, 60,0 \%$ presentaba fenotipo $\mathrm{NA}^{\mathrm{R}} / \mathrm{CIP}^{\mathrm{R}}, 14,2 \% \mathrm{NA}^{\mathrm{S}} / \mathrm{CIP}^{\mathrm{S}}$ y $11,4 \% \mathrm{NA}^{\mathrm{I}} / \mathrm{CIP}^{\mathrm{S}}$. Otros fenotipos se observaron en menor frecuencia (Tabla 2). La cepa portadora de qnrA mostró fenotipo $\mathrm{NA}^{\mathrm{R}} / \mathrm{CIP}^{\mathrm{R}}$.

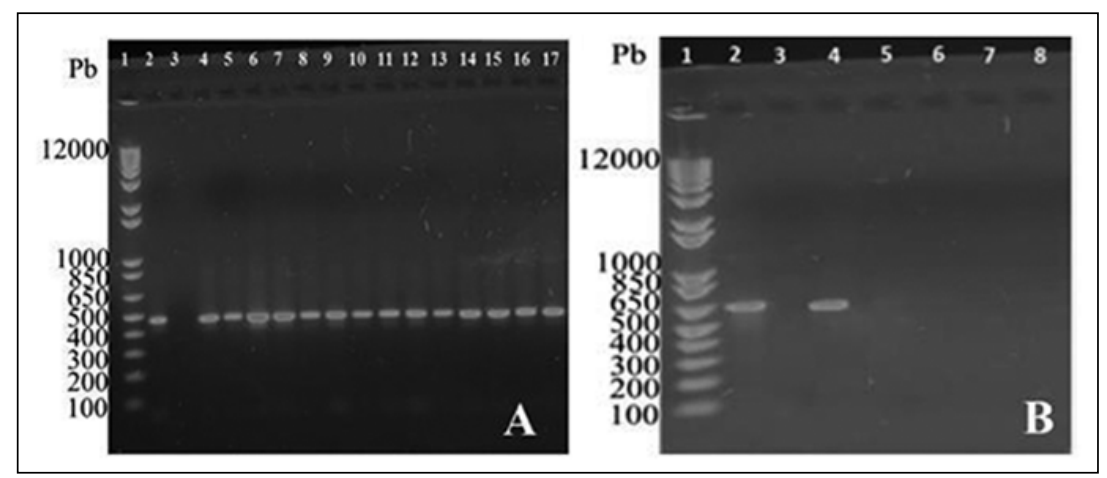

Figura 2. Productos de la amplificación del gen qnr en enterobacterias aisladas en muestras de pacientes asistidos en los diferentes servicios del Hospital Universitario "Antonio Patricio de Alcalá", Cumaná, estado Sucre. Enero - junio de 2014. A: gen qnrB. 1: marcador de tamaño molecular 1 Kb Plus (Invitrogen), 2: control positivo qnr168, 3: control negativo Escherichia.coli J62-2, 4 al 17: cepas clínicas. B: gen qnrA. 1: Marcador de tamaño molecular $1 \mathrm{~Kb}$ Plus (Invitrogen), 2: control positivo Klebsiella pneumoniae UAB1, 3:control negativo E. coli J62-2, 4: cepa 194.2, 5 al 8: cepas clínicas sin amplificados. 
Tabla 1. Distribución porcentual de la presencia de genes $q n r$ en enterobacterias aisladas de pacientes atendidos en los diferentes servicios del Hospital Universitario "Antonio Patricio de Alcalá", Cumaná, estado Sucre. Enero - junio de 2014

\begin{tabular}{lccccc|}
\hline Especie & $\mathbf{n}$ & $\mathbf{q n r A}$ & $\mathbf{9}$ & $\mathbf{n}$ & $\mathbf{q n}$ \\
\hline Escherichia coli & 0 & 0 & 16 & 15,38 \\
Klebsiella pneumoniae & 0 & 0 & 13 & 12,50 \\
\hline Enterobacter cloacae & 0 & 0 & 4 & 3,85 \\
Morganella morganii & 0 & 0 & 1 & 0,96 \\
Citrobacter freundii & 0 & 0 & 1 & 0,96 \\
Proteus vulgaris & 1 & 0,96 & 0 & 0,00 \\
Total & 1 & 0,96 & 35 & 33,65 \\
\hline
\end{tabular}

Tabla 2. Fenotipos de susceptibilidad antimicrobiana al ácido nalidíxico y ciprofloxacina en cepas portadoras de genes $q n r$

\begin{tabular}{|c|c|c|c|c|}
\hline & \multicolumn{4}{|c|}{ Genes } \\
\hline & \multicolumn{2}{|c|}{ qnrA } & \multicolumn{2}{|c|}{$q n r B$} \\
\hline & $\mathrm{n}$ & $\%$ & $n$ & $\%$ \\
\hline$N A^{s} / C I P^{s}$ & 0 & 0,00 & 5 & 4,81 \\
\hline$N A^{R} / C I P^{S}$ & 0 & 0,00 & 1 & 0,96 \\
\hline$N A^{R} / C I P^{R}$ & 1 & 0,96 & 21 & 20,19 \\
\hline$N A^{1 / C I P S}$ & 0 & 0,00 & 4 & 3,85 \\
\hline $\mathrm{NA}^{\mathrm{s}} / \mathrm{CIPI}$ & 0 & 0,00 & 1 & 0,96 \\
\hline$N A^{R} / C I P I$ & 0 & 0,00 & 3 & 2,88 \\
\hline Total & 1 & 0,96 & 35 & 33,65 \\
\hline
\end{tabular}

NA: ácido nalidixico, CIP: ciprofloxacina, S: sensible, I: intermedio, R: resistente, n: número, $\%$ : porcentaje.
Tabla 3. Perfil de resistencia antimicrobiana de cepas clínicas portadoras del gen qnr y sus respectivas transconjugantes

\begin{tabular}{|c|c|}
\hline Cepa & Perfil de resistencia \\
\hline EC7 & NA, CIP, LVX, NOR, CAZ \\
\hline $\mathrm{T7}$ & NR \\
\hline Kp33.2 & NA, CIP, LVX, NOR, CAZ, CTX, ATM, FEP \\
\hline T33.2 & $N A \mathrm{I}, C A Z, C T X, A T M$ \\
\hline ECL60.2 & NA, CIP, LVX, NOR, CAZ, CTX, ATM \\
\hline T60.2 & $N A^{I}, C A Z, C T X, A T M$ \\
\hline Kp74.1 & NA, CIP, LVX, NOR, CAZ, CTX, ATM \\
\hline T74.1 & $N A^{I}, C A Z, C T X, A T M$ \\
\hline EC74.2 & NA, CAZ, CTX, ATM \\
\hline T74.2 & NAI, CAZ, CTX, ATM \\
\hline Kp95 & NA, CIP, LVX, NOR, CAZ, CTX, ATM, FEP, AK \\
\hline T95 & $N A^{I}$ \\
\hline ECL101 & NA, CAZ, CTX, ATM, FEP, IMP, MEM, AK, GM \\
\hline T101 & $N A^{I}$ \\
\hline EC117 & NA, CIP, LVX, NOR, CAZ, CTX, ATM, FEP \\
\hline T117 & NR \\
\hline Kp121.1 & NA, CAZ, CTX, ATM \\
\hline T121.1 & $\mathrm{NA}^{\mathrm{I}}, \mathrm{CAZ}, \mathrm{CTX}, \mathrm{ATM}$ \\
\hline EC125 & NA, CTX \\
\hline T125 & $N A^{I}, C T X$ \\
\hline EC130 & NA, CIP, LVX, NOR, CAZ, CTX, ATM, FEP \\
\hline T130 & $N A^{\prime} C T X$ \\
\hline Kp147 & NA, CIP, LVX, NOR, CTX, AK, GM \\
\hline T147 & $N A^{I}, C T X$ \\
\hline Kp153.1 & NA \\
\hline T153.1 & NR \\
\hline EC153.2 & NA, CIP, LVX, NOR, CAZ, CTX \\
\hline $\mathrm{T} 153.2$ & $N A^{I}, C T X$ \\
\hline CF153.3 & $N A^{I}$ \\
\hline T153.3 & $N A^{I}$ \\
\hline Kp156.1 & NAI, CAZ, CTX, ATM, AK, GM \\
\hline T156.1 & CAZ, CTX, ATM, AK, GM \\
\hline EC180 & NA, CIP, LVX, NOR, GM \\
\hline T180 & $N A^{I}$ \\
\hline EC181 & NA, CIP, LVX, NOR, CAZ, CTX, ATM, FEP, GM \\
\hline T181 & NR \\
\hline Kp194.1 & NA, CIP, LVX, NOR, CAZ, CTX, ATM, FEP, AK, GM \\
\hline T194.1 & NR \\
\hline PV194.2 & NA, CIP, LVX, NOR, CAZ, CTX, ATM, FEP, AK, GM \\
\hline T194.2 & $\mathrm{NA}^{\mathrm{I}}, \mathrm{CTX}$ \\
\hline Kp202 & NA, CAZ, CTX, ATM, FEP, AK \\
\hline T202 & CAZ, CTX \\
\hline Kp228.1 & NA, CIP, LVX, NOR, CAZ, CTX, ATM, FEP, GM \\
\hline T228.1 & CAZ, CTX \\
\hline EC232 & $N A^{I}, C A Z, C T X$ \\
\hline T232 & $N A^{I}$ \\
\hline
\end{tabular}

T: transconjugante. EC: E. coli, KP: K. pneumoniae, MM: M. morganii, ECL: E. cloacae, PV: P. vulgaris, CF: C. freundii, NA: ácido nalidíxico, CIP: ciprofloxacina, LVX: levafloxacina, NOR: norfloxacina,CAZ: ceftazidima CTX: cefotaxima, ATM: aztreonam, FEP: cefepime, IMP: imipenem, MEM: meropenem, AK: amikacina, GM: gentamicina, I: intermedio, NR: no resistente. 


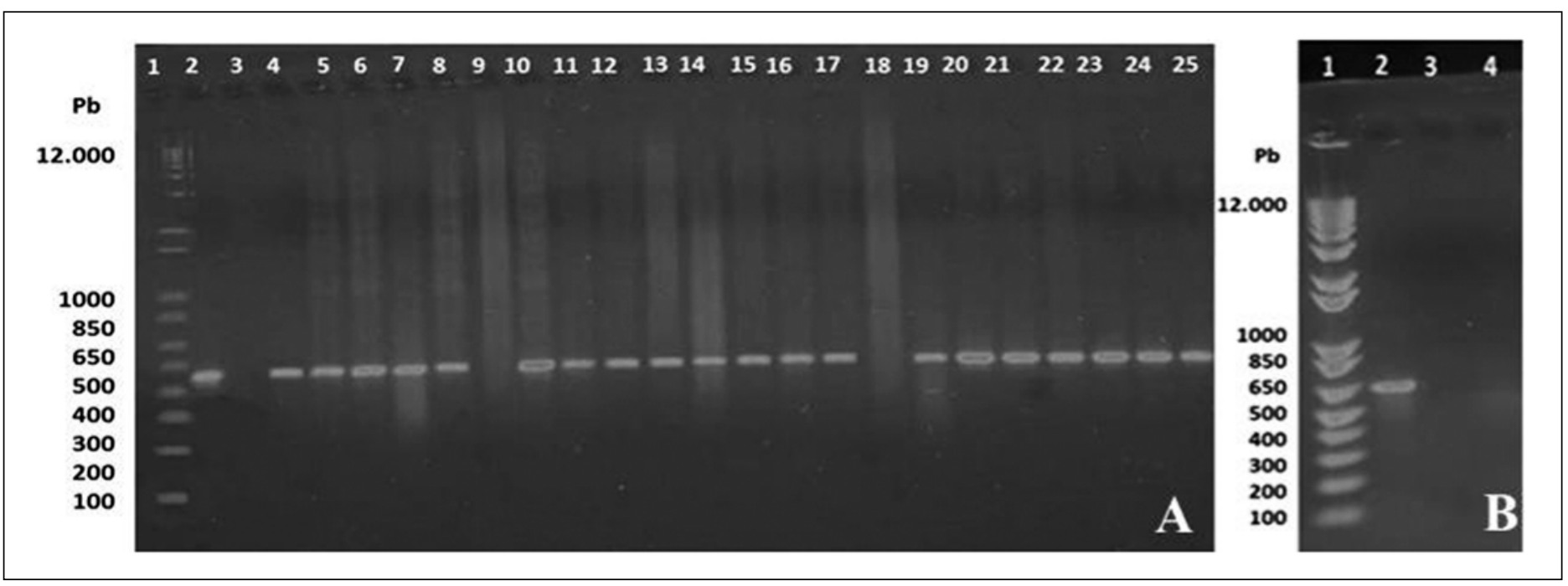

Figura 3. Productos de la amplificación del gen qnr en cepas transconjugantes. A: gen qnrB. 1: marcador de tamaño molecular $1 \mathrm{~Kb}$ Plus Invitrogen, 2: control positivo qnr168, 3: control negativo Escherichia coli J62-2, 4: cepa T7, 5: cepa T33.2, 6: cepa T60.2, 7: cepa T74.1, 8: cepa T74.2, 9: cepa T95, 10: cepa T101, 11: cepa T117, 12: сера T121.1, 13: сера T125, 14:сера T130, 15: сера T147, 16: сера T153.1, 17: сера T153.2, 18: сера T153.3, 19: cepa T156.1, 20: cepa T180, 21: cepa T181, 22: cepa T194.1, 23: cepa T202, 24:cepa T228.1, 25: cepa T232. B: gen qnrA. 1: marcador de tamaño molecular 1 Kb Plus Invitrogen, 2: control positivo Klebsiella pneumoniae UAB1, 3: control negativo E. coli J62-2, 4: cepa T194.2 no amplificó.

\section{Discusión}

La aplicación de quinolonas de manera indiscriminada en el campo de la salud, la agricultura y el procesamiento de alimentos, ha incidido en el incremento de los porcentajes de resistencia a estos antimicrobianos, especialmente en miembros de la familia Enterobacteriaceae, lo que puede deberse a la presencia de mecanismos que han sido localizados, ya sea a en el cromosoma y/o en plásmidos ${ }^{22}$.

En Latinoamérica, la resistencia a quinolonas ha sido reportada por diversos autores ${ }^{23-25}$. En el hospital donde se efectuó este estudio, la susceptibilidad antimicrobiana a quinolonas ha sido poco documentada, Guzmán y Alonso $^{26}$, describieron $14,0 \%$ de cepas de K. pneumoniae resistentes a ciprofloxacina. Posteriormente, Guzmán y cols. ${ }^{27}$, reportaron $14,8 \%$ de cepas de enterobacterias resistentes a ciprofloxacina, denotando que estos valores son inferiores a los obtenidos en este estudio, lo que permite inferir que en los últimos años en el centro hospitalario se han seleccionado y diseminado determinantes de resistencia a quinolonas, favorecidos probablemente por el uso indiscriminado de estos antimicrobianos.

Ha de destacarse que en esta investigación se evidenció que la resistencia de las cepas estudiadas no se limitó a quinolonas, sino también a otras familias de antimicrobianos como $\beta$-lactámicos y aminoglucósidos, situación que puede deberse a que estas cepas con frecuencia portan múltiples genes de resistencia plasmídicos de manera simultánea ${ }^{28,29}$.
La elevada frecuencia de genes $q n r$ detectados, revela que en el centro asistencial se encuentran circulando determinantes de resistencia a quinolonas diferentes a los originados por mutaciones cromosomales, que es el mecanismo que con más frecuencia se asocia la resistencia a estos antimicrobianos. Por otra parte, la presencia del gen $q n r$ en seis especies de enterobacterias, indica que estos genes presentan una distribución amplia entre los diferentes géneros bacterianos.

La frecuencia del gen $q n r \mathrm{~B}$, encontrada en este estudio es mayor a la reportada por otros investigadores en el país ${ }^{30,31}$. Mientras que la baja frecuencia del gen $q n r \mathrm{~A}$, observada en esta investigación, sí concuerda con lo reportado por otros autores en la región ${ }^{8,32}$. El predominio del gen $q n r \mathrm{~B}$ con respecto al $q n r \mathrm{~A}$, evidenciado en esta investigación, se encuentra dentro de lo esperado, ya que los estudios de frecuencia de genes $q n r$ en varios países de Latinoamérica indican que los alelos de los genes qnr $\mathrm{B}$ son más frecuentes ${ }^{33-35}$.

Los resultados indican que los genes qnr pueden estar albergados en cepas con patrones de susceptibilidad a quinolonas variables, siendo de gran importancia el hecho que en cepas sensibles a dichos antimicrobianos $\left(\mathrm{NA}^{\mathrm{S}}\right.$ / $\mathrm{CIP}^{\mathrm{S}}$ ) se demostró la presencia del gen qnrB. Este hallazgo revela que las cepas portadoras del gen son categorizadas como sensibles en el laboratorio microbiológico; por consiguiente, las quinolonas se considerarían como una opción terapéutica a nivel clínico. Sin embargo, el uso de estos agentes contra este tipo de cepas, además de 
representar un posible fracaso terapéutico, va a aportar la presión antimicrobiana necesaria para que se seleccionen cepas con mutaciones cromosómicas ${ }^{8,36,37}$. Los resultados obtenidos en este estudio sugieren la necesidad de regularizar los tratamientos antimicrobianos con quinolonas, a fin de minimizar la aparición de este tipo de cepas.

A través del proceso de conjugación, se pudo comprobar la capacidad de transferencia que presentan los plásmidos albergados en las enterobacterias portadoras de $q n r$, para establecerse en la célula receptora, independientemente del género original en el que se encontraban. Lo cual deja en evidencia el amplio rango de hospedador de estos plásmidos y representa desde el punto de vista clínico y epidemiológico un hallazgo importante, debido a que refleja la facilidad con que se estarían diseminando los genes $q n r$ entre las bacterias que cohabitan el centro hospitalario. Este hecho complica la utilización de quinolonas como opción terapéutica contra este tipo de microorganismos.

Las 15 cepas trans-conjugantes con susceptibilidad intermedia a quinolonas constituyen un hallazgo importante, ya que este patrón de resistencia ha sido asociado con la presencia de genes $q n r^{38,39}$. Al confirmar la presencia del gen $q n r$ en las cepas trans-conjugantes, y analizar los fenotipos de susceptibilidad que presentaban, se encontró que existe concordancia con lo postulado por algunos investigadores ${ }^{4,40}$, quienes señalan que las proteínas Qnr confieren resistencia al ácido nalidíxico más no a las fluoroquinolonas. Este hecho se pudo apreciar, ya que las trans-conjugantes carecen de mutaciones y, por tanto, el fenotipo observado de cepas con sensibilidad disminuida al ácido nalidíxico y sensibles a ciprofloxacina, es sólo producto de la acción del gen $q n r$ sin inteferencias de otros mecanismos.

La capacidad de transferencia de plásmidos portadores de genes $q n r$, ha sido documentada por diversos autores en el ámbito internacional ${ }^{18,41,42}$. En Venezuela, no se han reportado investigaciones relacionadas con la transferencia de genes qnr; el presente estudio representaría la primera evidencia sobre la transferencia de resistencia a quinolonas mediada por plásmidos.

La localización de los genes $q n r$ en elementos genéticos móviles, que a su vez transportan otros genes de resistencia, favorece la extensa diseminación de los mismos a otros aislados clínicos ${ }^{4,41,42}$. La presencia de $q n r$ y la resistencia a $\beta$-lactámicos observada en las cepas trans-conjugantes, sugiere que los genes que codifican para ambos mecanismos, pueden transferirse y expresarse de manera conjunta en las cepas que los albergan. Al respecto, algunos autores ${ }^{28,29,39}$ han descrito que los genes $q n r$ se transmiten de forma conjunta, en la mayoría de los casos, con genes que codifican enzimas de resistencia a $\beta$-lactámicos. En consecuencia, el empleo de las quinolonas y/o $\beta$-lactámicos en pacientes con este tipo de cepas, permitirían la selección de dichas cepas, por encontrarse estos genes localizados en el mismo elemento genético.

De igual forma, se comprobó en una cepa trasconjugante, resistencia a aminoglucósidos, la que también expresó resistencia a cefalosporinas (cefotaxima, ceftazidima) y aztreonan. La resistencia a aminoglucósidos con frecuencia se ha observado en combinación con otros antimicrobianos como quinolonas y $\beta$-lactámicos ${ }^{10,28,29,42}$. Sin embargo, en este estudio, la baja transferencia de determinantes de resistencia a aminoglucósidos, sugiere que los genes que codifican resistencia a estos agentes se encontraban insertados en plásmidos no transferidos, o que en las cepas clínicas resistentes a aminoglucósidos estén presentes otros mecanismos de resistencia no codificados en plásmidos, como pudieran ser una disminución de la acumulación intracelular del antimicrobiano o la alteración del sitio diana ${ }^{43}$.

La transmisibilidad de los plásmidos, en especial, aquellos que codifican mecanismos de resistencia a quinolonas, desde el punto de vista epidemiológico es de gran interés, ya que facilita la diseminación del mecanismo entre patógenos en un centro hospitalario determinado. En el SAHUAPA, quedó demostrada la existencia no sólo de mecanismos de resistencia a quinolonas mediadas por plásmidos, sino también a $\beta$-lactámicos y aminoglucósidos, los que pueden ser transferidos simultáneamente por conjugación asegurando la diseminación de los determinantes de resistencia y originando la aparición de cepas con resistencia a múltiples antimicrobianos.

Por todo lo antes expuesto, la elevada frecuencia de genes $q n r$, encontrada en esta investigación, representa una situación preocupante en el SAHUAPA, ya que los genes $q n r$ localizados en plásmidos transferibles, tienen la capacidad de diseminarse en el centro hospitalario. Adicionalmente, la presencia de cepas portadoras de estos genes, pero con sensibilidad a quinolonas, constituye un problema clínico, debido a que podrían considerarse a las quinolonas como terapia antimicrobiana y, por consiguiente, facilitar la selección de cepas con mutaciones a nivel cromosómico, lo que complica la aplicación de tratamientos con quinolonas en pacientes con infecciones por enterobacterias. Por lo tanto, es necesario que las autoridades sanitarias apliquen vigilancia epidemiológica y control de infecciones, a fin de minimizar la aparición y diseminación de estas cepas.

Agradecimientos. Al Laboratorio de Biología de Plásmidos de la Universidad Central de Venezuela (UCV), por donar las cepas control empleadas en esta investigación.

\section{Resumen}

Introducción: La resistencia de enterobacterias a quinolonas se ha difundido por el mundo, fenómeno 
presente también en Venezuela. El mecanismo de esta resistencia pudiera estar mediado por genes incluidos en el cromosoma bacteriano o transmitirse en el interior de plásmidos. Objetivo: Evaluar la resistencia a quinolonas, codificada por genes $q n r$, presentes en cepas de enterobacterias, aisladas en el Hospital Universitario de Cumaná, Venezuela. Métodos: A las cepas obtenidas se les realizaron pruebas de susceptibilidad antimicrobiana a quinolonas, $\beta$-lactámicos y aminoglucósidos. La presencia del gen $q n r$ se determinó por RPC. Las enterobacterias portadoras del gen $q n r$ fueron sometidas al proceso de conjugación bacteriana para comprobar su capacidad de transferencia. A las transconjugantes obtenidas se les realizó pruebas de susceptibilidad antimicrobiana y RPC para comprobar la transferencia de los genes. Resultados: Se encontraron elevados porcentajes de resistencia antimicrobiana a quinolonas y betalactámicos. El 33,6\% de las cepas eran portadoras del gen $q n r \mathrm{~B}$, y $0,9 \%$ del gen qnrA. Se obtuvieron 23 cepas transconjugantes; de éstas, 20 portaban el gen $q n r \mathrm{~B}$, no se observó la presencia de qnrA. Discusión: En conclusión, el elevado porcentaje de genes $q n r$ encontrado en las enterobacterias aisladas, y comprobada la presencia de éstos en plásmidos transferibles, complica la aplicación de tratamientos basados en quinolonas y fluoroquinolonas, por lo que es recomendable el uso racional de estos antimicrobianos, y proponer la rotación de la terapia antimicrobiana, a fin de evitar la selección de cepas resistentes.

\section{Referencias bibliográficas}

1.- Alós J. Quinolonas. Enferm Infecc Microbiol Clin 2003; 21: 261-7.

2.- Wright D, Brown G, Peterson M, Rotschafer J. Application of fluoroquinolone. pharmacodynamics 2000; 46: 669-83.

3.- King D E, Malone R, Lilley S H. New classification and update on the quinolone antibiotics. am fam physician 2000; 61 (9): 2741-48.

4.- Rodríguez-Martínez J, Briales A, Velasco C, Conejo L, Martínez-Martínez A. Mutational analysis of quinolone resistance in the plasmidencoded pentapeptide repeat proteins QnrA, QnrB and $Q n r S$. J Antimicrob Chemother 2009; 63 (6): 1128-34. doi: 10.1093/jac/dkp111.

5.- Nordmann P, Poirel L. Emergence of plasmid-mediated resistance to quinolones in Enterobacteriaceae. J Antimicrob Chemother 2005; 56: 463-9. DOI: 10.1093/jac/dki245.

6.- Jacoby G, Walsh K, Mills D, Walker V, Oh $\mathrm{H}$, Robicsek A, et al. qnr B, Another plasmidmediated gene for quinolone resistance. Antimicrob Agents Chemother 2006; 50: 117882. DOI: 10.1128/AAC.50.4.1178-1182.2006.

7.- Wang M, Guo Q, Xu X, Wang X, Ye X. New plasmid-mediated quinolone resistance gene, $q n r \mathrm{C}$, found in a clinical isolate of Proteus mirabilis. Antimicrob Agents Chemother 2009; 53 (5): 1892-97. doi: 10.1128/AAC.01400-08.

8.- Castanheira M, Pereira A, Nicoletti A, Pignatari A, Barth A, Gales A. First report of plasmidmediated qnrA1 in a ciprofloxacin-resistant Escherichia coli strain in Latin America. Antimicrob Agents Chemother 2007; 51: 15279. doi:10.1128/AAC.00780-06.

9.- Pons M J, Gomes C, Ruiz J. QnrVC, a new transferible Qnr-like family. Enferm Infecc Microbiol Clin 2013; 31 (3): 191-2. doi: 10.1016/j.eimc.2012.09.008.

10.- Robicsek A, Trahilevitz J, Jacoby G, Macielag M, Abbanat D, Park CH, et al.
Fluoroquinolonas modificación de la enzima: una nueva adaptación de un aminoglucósido acetiltransferasa común. Nat Med 2006; 12: 83-8.

11.- Strahilevitz J, Jacoby G, Hooper D, Robicsek A. Plasmid-mediated quinolone resistance: a multifaceted threat. Clin Microbiol Rev 2009; 22: 664-89. doi: 10.1128/ CMR.00016-09.

12.- Piekarska K, Rzeczkowska M, Zacharczuk K, Chróst A, Januszkiewicz A, Bareja E, et al. Prevalence of $q n r$ genes in clinical Enterobacteriaceae non-susceptible to fluoroquinolone in Poland. Med Dosw Mikrobiol 2012; 64: 211-9.

13. González F, Pallecchi L, Rossolini G, Araque M. Plasmid-mediated quinolone resistance determinant $q n r \mathrm{~B} 19$ in non-typhoidal Salmonella enterica strains isolated in Venezuela. J Infect Dev Ctries 2012; 6: 462-4.

14.- Koneman E, Allen S, Dawell V, Janda W, Sommers H, Winn W, et al. Capítulo 4: Enterobacteriaceae Diagnóstico Microbiológico Texto y atlas en color. Buenos Aires: Editorial Médica Panamericana; 2008, p. 171-242.

15.- Mac Faddin, J. 2003. Pruebas bioquímicas para la identificación de bacterias de importancia clínica. México: Editorial Médica Panamericana; 2003.

16.- Clinical and Laboratory Standards Institute (CLSI). Performance standards for antimicrobial susceptibility testing; twentyfourth informational supplement M100-S24. Pennsylvania, USA; 2014.

17.- Hong Z, Ding H, Deng Q, Wang C, Lan L, Xiwei X, et al. Presence of $q n r$ gene in Escherichia coli and Klebsiella pneumoniae resistant to ciprofloxacin isolated from pediatric patients in China. BMC Infect Dis 2008; 8: 1-6. doi: 10.1186/1471-2334-8-68

18.- Wang M, Sahm D, Jacoby G, Hooper D Emerging plasmid-mediated quinolone resistance associated with the $q n r$ gene in Klebsiella pneumoniae clinical isolates in the United States. Antimicrob Agents Chemother 2004; 48: 1295-9. doi: 10.1128/ AAC.48.4.1295-1299.2004

19.- Pedroza R, Cuotto W, Velázquez O, Torres L, Rodríguez L. Caracterización de plásmidos de Acinetobacter baumannii en tres centros hospitalarios. Rev Fac Med 2002; 25: 80-2.

20.- Yang H, Nam Y, Lee H. Plasmid mediated quinolone resistance in Korea. Can J Infect Dis Med Microbiol 2014; 25 (3): 69-79. doi: 10.1089/mdr.2015.0090

21.- Dawson S, Robert G. Bioestadística Médica. Ciudad de México. Editorial el Manual Moderno S.A.; 1997.

22.- Álvarez D, Garza G, Vázquez R. Quinolonas. Perspectivas actuales y mecanismos de resistencia. Rev Chilena Infectol 2015; 32: (5): 499-504. http://dx.doi.org/10.4067/S071610182015000600002.

23.- López B, Calderón E, Olivar V, Parra I, Alcáza V, Castellanos M, et al. Susceptibilidad antimicrobiana de microorganismos causantes de infección de vías urinarias bajas en un hospital pediátrico. Bol Med Hosp Infant Mex 2014; 71 (6): 339-45. http://dx.doi. org/10.1016/j.bmhimx.2015.01.001

24.- Suárez B, Milián Y, Espinosa F, Hart M, Llanes N, Martínez M. Susceptibilidad antimicrobiana y mecanismos de resistencia de Escherichia coli aisladas a partir de urocultivos en un hospital de tercer nivel. Rev Cubana Med Gen Integr 2014; 53: 3-13.

25.- Torres G, Brito B, Barbier A. Comportamiento de la infección urinaria y susceptibilidad antimicrobiana de la bacteria más frecuente. Rev Cubana Med Gen Integr 2014; 30 (4): 41625.

26.- Guzmán M, Alonso G. Integrones clase 1 asociados a plásmidos en cepas de Klebsiella pneumoniae. Bol Soc Ven Microbiol 2010; 28 : 105-09. 
27.- Guzmán M, Rodríguez E, Antón K, Silva S, Navarro J, Lastra L, et al. Genes blaTEM, blaSHV y blaCTX-M en enterobacterias productoras de $\beta$-lactamasas de espectro extendido aisladas de pacientes con infección intrahospitalaria. Rev Invest Clin 2013; 54 (3): 235-45.

28.- Bouchakour M, Zerouali K, Perrier J, Claude G, Amarouch H, El Mdaghri N, et al. Plasmid-mediated quinolone resistance in expanded spectrum beta lactamase producing Enterobacteriaceae in Morocco. J Infect Dev Ctries 2010; 4 (12): 799-803.

29.- Pitout J, Wei Y, Church D, Gregson D. Surveillance for plasmid-mediated quinolone resistance determinants in Enterobacteriaceae within the Calgary Health Region, Canada: the emergence of $a a c\left(6^{\prime}\right)-I b-c r$. J Antimicrob Chemother 2008; 61: 999-1002. DOI: 10.1093/ $\mathrm{jac} / \mathrm{dkn} 068$

30.- Chivico M. Identificación de la presencia de genes plasmídicos qnr que confieren resistencia a quinolonas en cepas de Escherichia coli causantes de infecciones de tracto urinario con expresión de ß-lactamasas de espectro extendido. Universidad Central de Venezuela, Caracas, Venezuela, 2009. (Accedido el 14 de marzo de 2016). Disponible en: http://saber. ucv.ve/bitstream/123456789/8998/1/Tesis\%20 Marilin\%20E.\%20Chivico.pdf.

31.- Marcano D. Relación entre la producción de betalactamasas de espectro expandido (BLEE) y la resistencia a fluoroquinolonas en cepas de enterobacterias provenientes de centros hospitalarios de Venezuela. Universidad del Zulia, Zulia, Venezuela; 2011. (Accedido el 16 de marzo de 2016). Disponible en:http://tesis. luz.edu.ve/tde arquivos/52/TDE-2012-0424T10:07:41Z-2835/publico/marcano_zamora_ daniel.pdf.
32.- Ferrari R, Galiana A, Cremades R, Rodríguez J, Magnan M, Tognim M, et al. Plasmid-mediated quinolone resistance (PMQR) and mutations in the topoisomerase genes of Salmonella enterica strains from Brazil. Braz J Microbiol 2013; 44: 657-62. doi: 10.1590/S151783822013000200046 .

33.- Pallecchi L, Bartoloni A, Fiorelli C, Mantella A, Di Maggio T, Gamboa H, et al. Rapid dissemination and diversity of CTX-M extended-spectrum $\beta$-lactamase genes in commensal Escherichia coli isolates from healthy children from low resource settings in Latin America. Antimicrob Agents Chemother 2007; 51:2720-5. doi: 10.1128/ AAC.00026-07

34.- Escobar A, Porto A, Joris R, Sansevich M, Gutkind G, Di Conza J, et al. Detección de genes $q n r$ en aislamientos de enterobacterias con resistencia simultánea a fluoroquinolonas y oximinocefalosporinas. FABICIB 2010; 14 : 39-45.

35.- Rincón G, Radice M, Sennati S, Pallecchi L, Rossolini M, Gutkind G, et al. Prevalence of plasmid-mediated quinolone resistance determinants among oxyiminocephalosporinresistant Enterobacteriaceae in Argentina. Mem Inst Oswaldo Cruz 2014; 7: 924-7. doi: 10.1590/0074-0276130084

36.- Minarini L, Poirel L, Cattoir V, Darini A, Nordmann P. Plasmid-mediated quinolone resistance determinants among enterobacterial isolates from outpatients in Brazil. J Antimicrob Chemother 2008; 62: 474-8. doi: 10.1093/jac/ dkn237

37.- Cavaco L, Hasman H, Xia S, Aarestrup F. $q n r \mathrm{D}$, a novel gene conferring transferable quinolone resistance in Salmonella enteric serovars Kentucky and Bovis morbificans of human origin. Antimicrob Agents Chemother
2009; 53: 603-8. doi: 10.1128/AAC.00997-08

38.- Rodríguez-Martínez M, Pichardo C, García I, Pachón-Ibañez M, Docobo F, Pascual A. Activity of ciprofloxacin and levofloxacin in experimental pneumonia caused by Klebsiella pneumoniae deficient in porins, expressing active efflux and producing $q n r \mathrm{~A} 1$. Clin Microbiol Infect 2008; 14: 691-7. doi: 10.1111/j.1469-0691.2008.02020.x.

39.- Hernández M, Yagüe G, Muñoz J, Fernández M, Segovia M. Prevalencia de genes codificadores de resistencia a fluoroquinolonas de localización plasmídica (RPFQ) en enterobacterias aisladas en la Región de Murcia. Rev Esp Quimioterap 2013; 43 (4): 150-75.

40.- Nordmann P, y Poirel L. Emergence of plasmid-mediated resistance to quinolones in Enterobacteriaceae. J Antimicrob Chemother 2005; 56: 463-9. DOI: 10.1093/jac/dki245.

41.- Wang A, Yang Y, Lu Q, Wang Y, Chen Y, Deng L, et al. Presence of $q n r$ gene in Escherichia coli and Klebsiella pneumoniae resistant to ciprofloxacin isolated from pediatric patients in China. BMC Infect Dis 2008; doi: 10.1186/1471-2334-8-68.

42.- Jiang X, Li J, Zhang Y, Yan H, Wang Y, Shi L, et al. Detection of plasmid-mediated quinolone resistance determinants and $q n r \mathrm{~S}$ expression in Enterobacteriaceae clinical isolates. J Infect Dev Ctries 2014; 8 (12): 1625-9.

43.- Navarro F, Calvo J, Cantón R, Fernández-Cuenca F, Mirelis, B. Detección fenotípica de mecanismos de resistencia en Gramnegativos. En: Cantón R, Cercenado E, editores. Procedimientos en microbiología clínica. Recomendaciones de la Sociedad Española de Enfermedades Infecciosas y Microbiología Clínica. SEIMC 2011; 29 (7): 524-34. 